\title{
Article \\ Clinical Outcome and Risk Factors of Red Blood Cell Transfusion in Patients Undergoing Elective Primary Meningioma Resection
}

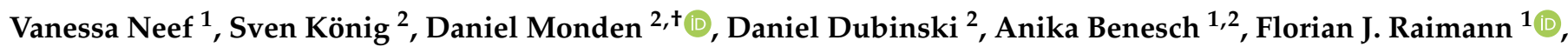 \\ Florian Piekarski ${ }^{1}$ (D) Michael W. Ronellenfitsch ${ }^{3}$ (D) Patrick N. Harter ${ }^{4}$, Christian Senft ${ }^{2,+} \mathbb{D}$, \\ Patrick Meybohm 1, ${ }^{(\mathbb{D}}$, Elke Hattingen ${ }^{5}\left(\mathbb{D}\right.$, Kai Zacharowski ${ }^{1}$, Volker Seifert ${ }^{2}$ and Peter Baumgarten ${ }^{2, *,+} \mathbb{D}^{\mathbb{D}}$
}

Citation: Neef, V.; König, S.; Monden, D.; Dubinski, D.; Benesch, A.; Raimann, F.J.; Piekarski, F.; Ronellenfitsch, M.W.; Harter, P.N.; Senft, C.; et al. Clinical Outcome and Risk Factors of Red Blood Cell Transfusion in Patients Undergoing Elective Primary Meningioma Resection. Cancers 2021, 13, 3601. https://doi.org/10.3390/ cancers 13143601

Academic Editor: Oliver Schnell

Received: 25 April 2021

Accepted: 15 July 2021

Published: 18 July 2021

Publisher's Note: MDPI stays neutral with regard to jurisdictional claims in published maps and institutional affiliations.

Copyright: (c) 2021 by the authors. Licensee MDPI, Basel, Switzerland. This article is an open access article distributed under the terms and conditions of the Creative Commons Attribution (CC BY) license (https:// creativecommons.org/licenses/by/ $4.0 /)$
1 Department of Anaesthesiology, Intensive Care Medicine and Pain Therapy, University Hospital Frankfurt, Goethe University Frankfurt, 60590 Frankfurt, Germany; Vanessa.Neef@kgu.de (V.N.); Anika.Benesch@gmx.de (A.B.); Florian.Raimann@kgu.de (F.J.R.); Florian.Piekarski@kgu.de (F.P.); Meybohm_P@ukw.de (P.M.); Kai.Zacharowski@kgu.de (K.Z.)

2 Department of Neurosurgery, University Hospital, Goethe University Frankfurt, 60528 Frankfurt am Main, Germany; s8855616@stud.uni-frankfurt.de (S.K.);

Daniel.Monden@med.uni-jena.de (D.M.); daniel.dubinski@med.uni-rostock.de (D.D.); christian.senft@med.uni-jena.de (C.S.); v.seifert@em.uni-frankfurt.de (V.S.)

3 Dr. Senckenberg Institute of Neurooncology, University Hospital Frankfurt, Goethe University Frankfurt, 60528 Frankfurt am Main, Germany; Michael.Ronellenfitsch@kgu.de

4 Neurological Institute (Edinger Institute), University Hospital, Goethe University Frankfurt, 60528 Frankfurt am Main, Germany; patrick.harter@kgu.de

5 Department of Neuroradiology, University Hospital, Goethe University Frankfurt, 60528 Frankfurt am Main, Germany; elke.hattingen@kgu.de

* Correspondence: peter.baumgarten@med.uni-jena.de; Tel.: +49-(0)3641-9323011

+ Current affiliation: Department of Neurosurgery, University Hospital, Schiller University Jena, 07747 Jena, Germany.

$\ddagger$ Current affiliation: Department of Anaesthesiology, Intensive Care, Emergency and Pain Medicine University Hospital Wuerzburg, 97080 Wuerzburg, Germany.

Simple Summary: The transfusion of red blood cells (RBC) in patients undergoing major elective cranial surgery is associated with increased morbidity and mortality. This study sought to identify the clinical outcome of RBC transfusions in skull base and non-skull base meningioma patients including the identification of risk factors for RBC transfusion. Data underline that preoperative anaemia rate was significantly higher in transfused patients $(17.7 \%)$ compared to patients without RBC transfusion $(6.2 \%)$. We could further show that RBC transfusion was associated with increased postoperative complications and increased hospital length of stay. After multivariate analyses, risk factors for RBC transfusion were preoperative American Society of Anaesthesiologists (ASA) physical status score, tumor size, surgical time, and intraoperative blood loss. We concluded that blood loss due to large tumors or localization near large vessels are the main triggers for RBC transfusion in meningioma patients paired with a potential preselection that masks the effect of preoperative anaemia in multivariate analysis. So far, this has not been investigated in a large cohort $(n=423)$ of skull base and non-skull base meningioma patients.

Abstract: Transfusion of red blood cells (RBC) in patients undergoing major elective cranial surgery is associated with increased morbidity, mortality and prolonged hospital length of stay (LOS). This retrospective single center study aims to identify the clinical outcome of RBC transfusions on skull base and non-skull base meningioma patients including the identification of risk factors for RBC transfusion. Between October 2009 and October 2016, 423 patients underwent primary meningioma resection. Of these, $68(16.1 \%)$ received $\mathrm{RBC}$ transfusion and $355(83.9 \%)$ did not receive $\mathrm{RBC}$ units. Preoperative anaemia rate was significantly higher in transfused patients (17.7\%) compared to patients without RBC transfusion $(6.2 \% ; p=0.0015)$. In transfused patients, postoperative complications as well as hospital LOS was significantly higher $(p<0.0001)$ compared to non-transfused patients. After multivariate analyses, risk factors for RBC transfusion were preoperative American Society 
of Anaesthesiologists (ASA) physical status score $(p=0.0247)$, tumor size $(p=0.0006)$, surgical time $(p=0.0018)$ and intraoperative blood loss $(p<0.0001)$. Kaplan-Meier curves revealed significant influence on overall survival by preoperative anaemia, RBC transfusion, smoking, cardiovascular disease, preoperative KPS $\leq 60 \%$ and age (elderly $\geq 75$ years). We concluded that blood loss due to large tumors or localization near large vessels are the main triggers for RBC transfusion in meningioma patients paired with a potential preselection that masks the effect of preoperative anaemia in multivariate analysis. Further studies evaluating the impact of preoperative anaemia management for reduction of RBC transfusion are needed to improve the clinical outcome of meningioma patients.

Keywords: anaemia; red blood cells; transfusion; meningioma

\section{Introduction}

Preoperative anaemia is common in patients scheduled for major surgery, with a prevalence of up to $50 \%$ [1]. In patients undergoing a variety of non-neurosurgical procedures, recent studies revealed that preoperative anaemia is an independent risk factor for postoperative morbidity, mortality, prolonged hospital length of stay (LOS) and an increased risk for red blood cell (RBC) transfusions [2]. Given the sensitivity of the central nervous system to decreased oxygen delivery, especially neurosurgical patients have an increased anaemia vulnerability. This has been demonstrated in emergency situations like traumatic brain injury or subarachnoid haemorrhage [3,4]. Preoperative anaemia is frequent in patients undergoing major elective surgery with $28.7 \%$ [5]. A recent study by Bydon et al. revealed that of 8015 patients who underwent elective craniotomy for malignant tumor resection, 1710 patients $(21.4 \%)$ were anaemic (anaemia defined by haemoglobin $(\mathrm{Hb})$ value $<11 \mathrm{~g} / \mathrm{dL}$ for women and $<13 \mathrm{~g} / \mathrm{dL}$ for men). In addition, anaemia was associated with increased 30-day morbidity and mortality in patients [6].

Overall, transfusion of RBC units remains the main treatment of anaemia in surgical patients. Complications associated with RBC transfusions itself are transfusion related lung injury, haemolytic reactions or transmission of infectious disease, among others [7]. Regarding patient's clinical outcome RBC transfusions in elective cranial surgery are associated with prolonged hospital LOS, increased complication rate and 30-day mortality [8].

With a prevalence of almost one-third among brain tumors, meningiomas are one of the most frequent of all intracranial neoplasms most likely deriving from the meningothel of the arachnoid layer [9]. According to an analysis of patients who underwent craniotomy for resection of skull base meningiomas, 7 out $37(18.7 \%)$ patients received RBC transfusions. Here, the transfused patients stayed longer in hospital compared to patients without RBC transfusion (19.9 vs. 4.9 days). In addition, the skull base was an independent risk factor for transfusion after considering meningioma size [10].

Until now, there are large numbers of studies focusing on the impact of anaemia and RBC transfusions in subarachnoid haemorrhage or traumatic brain injury [11-14]. In meningiomas so far, the impact of anaemia and RBC transfusions has only been investigated in a small patient population with skull base meningiomas [10].

This retrospective study aims to identify the clinical outcome of RBC transfusions in patients undergoing elective neurosurgical resection of skull base and non-skull base meningiomas including risk factors for $\mathrm{RBC}$ transfusion.

\section{Materials and Methods}

\subsection{Patient Data}

We retrospectively analyzed patients undergoing primary meningioma resection at the University Hospital Frankfurt from October 2009 to October 2016. All patients received standard perioperative care. Data were extracted from the electronic hospital information system. 
Extracted data were preoperative patient specifics like age, sex, body mass index (BMI), American Society of Anaesthesiologists (ASA) physical status score, comorbidities and preoperative Karnofsky performance scale (KPS). For preoperative KPS we used a cutoff of $\leq 60 \%$ since that means independence of help for the daily life. Tumor related variables included prevalence of seizures, edema, embolization, tumor localization, histological brain invasion, histological subtype, Ki67-proliferation rate, mitosis count per 10 highpower fields (HPF), World Health Organization (WHO) grade and tumor size. WHO grade was histologically assessed according to the present WHO classification of central nervous system tumors [9]. Tumors were volumetriated on contrast enhanced T1 weighted magnetic resonance images (MRI) and edema was re-evaluated as suggested by Wirsching et al. on T2 weighted MRI images [15]. All WHO grades II and III meningiomas were histologically re-evaluated by at least two neuropathologists as published before in the same cohort [16].

Histological re-evaluation was performed with special attention on mitosis and histological brain invasion. Regarding surgical parameters, brain invasion defined as lack of arachnoid layer, and the extend of resection classified by the Simpson score were assessed. The Simpson score ranges from 1 to 5 , and is defined as following: complete tumor removal and its attachments (1), complete tumor removal with denaturation of its attachments (2), complete intracranial tumor resection but leaving tumor in the cranial sinuus and/or without denaturation of attachments (3), incomplete tumor removal (4) and biopsy and/or decompression without tumor removal (5) [17]. Intraoperative parameters included intraoperative blood loss and surgical time. Postoperatively extracted data were hospital LOS, intensive care unit (ICU) LOS, and postoperative complications (acute renal failure, pneumonia, sepsis, pulmonary embolism, myocardial infarction, stroke, seizures, and re-craniotomy due to bleeding or swelling). Haematological and transfusion related parameters were $\mathrm{Hb}$ value at hospital admission and discharge as well as the perioperative transfusion rate of RBCs, platelets, fresh frozen plasma (FFP), fibrinogen and prothrombin complex concentrate (PCC). For follow up, the patients were seen in the outpatient clinic after three, nine, and twelve months. After this period, they were seen yearly or every two years depending on $\mathrm{WHO}$ grade and recurrent tumor growth.

\subsection{Anaemia Classification}

In the present study, anaemia was defined according to the WHO definition of anaemia. Here anaemia is defined as a $\mathrm{Hb}$ concentration of $<12 \mathrm{~g} / \mathrm{dL}$ in women and $<13 \mathrm{~g} / \mathrm{dL}$ in men [18].

\subsection{Endpoints}

Primary endpoints were the prevalence of preoperative anaemia and perioperative RBC transfusion rate. Secondary endpoints were hospital LOS and ICU LOS, postoperative complications, anaemia rate at hospital discharge and perioperative transfusion rate of other blood products (platelets, FFP, fibrinogen and PCC).

\subsection{Statistical Analysis}

Statistical analysis and figure editing were performed using JMP 14.0 software (SAS Institute, Cary, NC, USA), GraphPad Prism 6 (GraphPad Software Inc., La Jolla, CA, USA) and the open-source GIMP2 program. Evaluation of the immunohistochemical preparations was performed using a BX50 light microscope (Olympus, Tokyo, Japan). Tumor volumetriation was performed using the SmartBrush tool of the Brainlab Elements software (Brainlab AG, Munich, Germany).

Descriptive statistical methods mean $( \pm \mathrm{SD})$ or median and interquartile range (IQR) (25-75\%) were used to analyze data. Shapiro-Wilk test was used to assess normality of continuous variables. Normally distributed continuous variables $(\mathrm{Hb}$ value at hospital discharge) were compared with the two-sided T-test. Non-normally distributed continuous variables were compared with Mood's median test. Categorical variables were compared with Pearson's Chi Square test. For multivariate analysis, logistic regression was conducted. 
Survival analyses were performed using Kaplan-Meier analyses. To compare the survival curves, we used Wilcoxon and log-rank tests for censored data. A $p$-value $<0.05$ was considered statistically significant.

\section{Results}

\subsection{Patient Cohort}

Overall, 555 surgeries for meningioma disease were performed, of which 66 patients with recurrent tumors, 53 spinal cases and 13 patients with no preoperative $\mathrm{Hb}$ value were excluded from further evaluation. The remaining 423 patients were included in final analysis (Figure 1). The median follow-up period in this study cohort was 15 months (mean: 21.7 months, IQR: 12-35 months, range: 0-98 months).

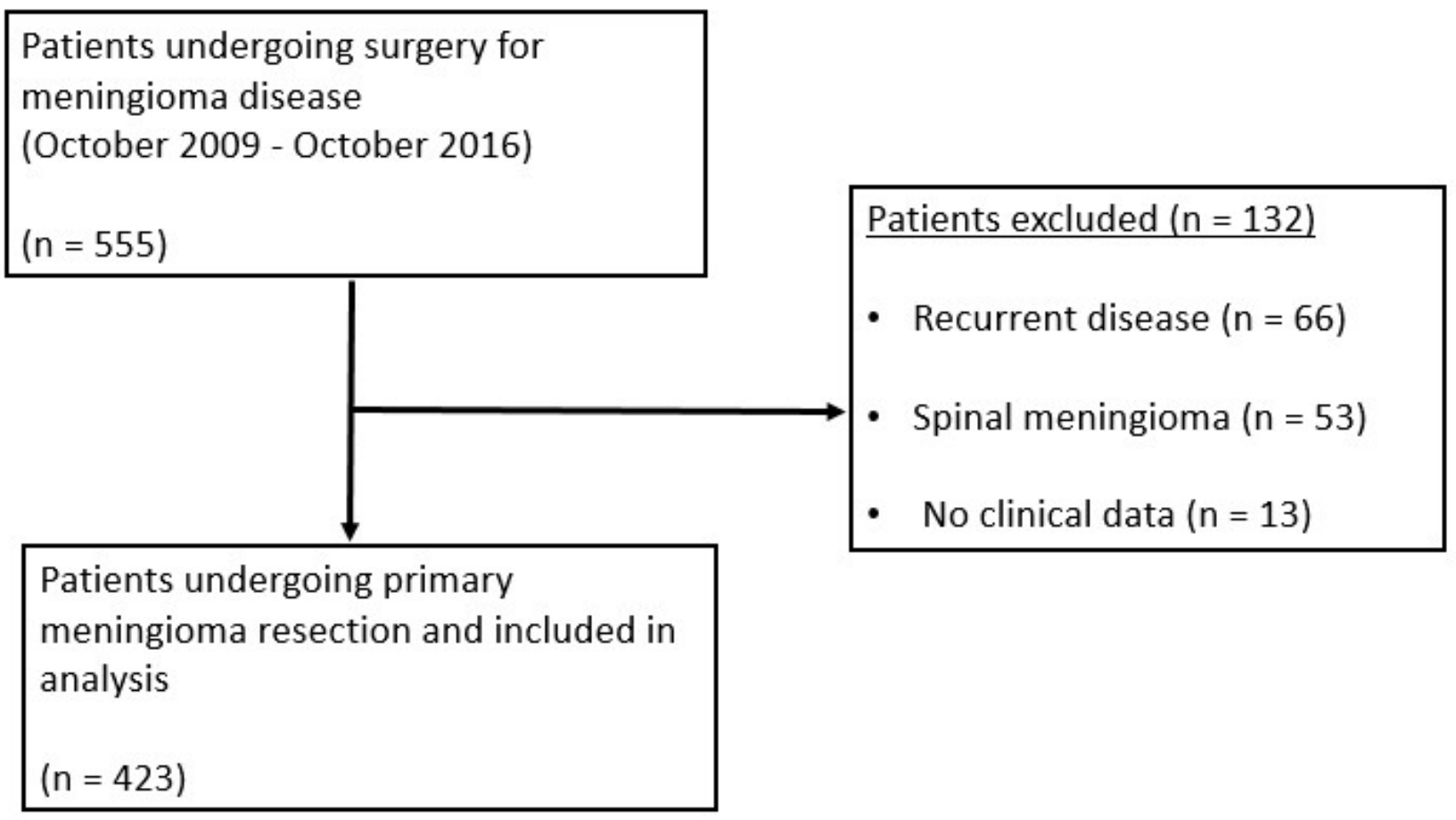

Figure 1. Flow chart of the selection process and overview of the study population.

\subsection{Patient and Meningioma Characteristics Between the RBC Transfusion and Non-RBC Transfusion Group}

Overall, 68 out of $423(16.1 \%)$ patients received perioperative RBC transfusion and 355 out of $423(83.9 \%)$ patients did not receive RBC transfusion. Median age in transfused patients was significantly higher (63 (51-71) years) compared to patients without RBC transfusion (56 (47-66) years; $p=0.0153$ ). The rate of elderly patients ( $\geq 75$ years) also differed significantly between the RBC transfusion group and non-RBC transfusion group $(13.2 \%$ vs. $4.5 \% ; p=0.0068)$. The prevalence of comorbidities differed significantly between the two groups regarding cardiovascular disease $(p=0.0107)$ and diabetes $(p=0.0210)$. In addition, tumor size was significantly higher in the RBC transfusion group (64.9 (34.5-84.5) $\mathrm{cm}^{3}$ ) compared to the non-RBC transfusion group (19.2 (7.6-40.4) $\left.\mathrm{cm}^{3} ; p<0.0001\right)$ (Table 1).

3.3. Hb Values, Transfusion Rates and Postoperative Complications Between the RBC Transfusion and Non-RBC Transfusion Group

Overall, 34 out of $423(8 \%)$ patients suffered from preoperative anaemia and 389 out of 423 patients (92\%) did not have preoperative anaemia. Preoperative anaemia rate was significantly higher in the RBC transfusion group compared to the non-RBC transfusion group $17.7 \%(n=12)$ vs. $6.2 \%(n=22) ; p=0.0015)$. 
Table 1. Demographic and meningioma data, postoperative complications, and transfusion rates between the RBC transfusion and non-RBC transfusion group.

\begin{tabular}{|c|c|c|c|}
\hline Characteristic & $\begin{array}{l}\text { RBC-Transfusion } n(\%) \\
68(16.1 \%)\end{array}$ & $\begin{array}{c}\text { Non-RBC Transfusion } n(\%) \\
(83.9 \%)\end{array}$ & $p$-Value \\
\hline Male/Female & $25(36.8 \%) / 43(63.2 \%)$ & $112(31.5 \%) / 243(68.5 \%)$ & $=0.4039$ \\
\hline Age (years) * & $63(51-71)$ & $56(47-66)$ & $=0.0153$ \\
\hline Elderly ( $\geq 75$ years) & $9(13.2 \%)$ & $16(4.5 \%)$ & $=0.0068$ \\
\hline $\operatorname{BMI}\left(\mathrm{kg} / \mathrm{m}^{2}\right) *$ & $26.3(22.8-38.9)$ & $26.3(23.1-33.5)$ & $=0.9825$ \\
\hline ASA score $* *$ & $\begin{array}{c}1(1.8 \%) / 24(42.1 \%) / 30 \\
(52.6 \%) / 2(3.5 \%)\end{array}$ & $\begin{array}{c}45(15.0 \%) / 181(60.3 \%) / 73 \\
(24.3 \%) / 1(0.3 \%)\end{array}$ & $<0.0001$ \\
\hline \multicolumn{4}{|l|}{ Comorbidities } \\
\hline Smoking & $14(20.6 \%)$ & $69(19.4 \%)$ & $=0.8264$ \\
\hline Cardiovascular disease & $35(51.5 \%)$ & $124(34.9 \%)$ & $=0.0107$ \\
\hline Pulmonary disease & $8(11.8 \%)$ & $23(6.6 \%)$ & $=0.1583$ \\
\hline Diabetes & $13(19.1 \%)$ & $32(9.1 \%)$ & $=0.0210$ \\
\hline Endocrine disorders & $28(41.2 \%)$ & $105(29.6 \%)$ & $=0.0676$ \\
\hline Chronic kidney injury & $21(30.9 \%)$ & $94(26.6 \%)$ & $=0.4273$ \\
\hline Coagulopathy & $2(2.9 \%)$ & $2(0.6 \%)$ & $=0.1167$ \\
\hline Preoperative seizure ${ }^{* *}$ & $16(25 \%)$ & $80(23.5 \%)$ & $=0.8008$ \\
\hline \multicolumn{4}{|l|}{ Meningioma } \\
\hline Non-Skull-Base/Skull-Base & $40(58.8 \%) / 28(41.2 \%)$ & $231(65.1 \%) / 124(34.9 \%)$ & $=0.3290$ \\
\hline Tumor size $\left(\mathrm{cm}^{3}\right) *$ & $64.9(34.5-84.5)$ & $19.2(7.6-40.4)$ & $<0.0001$ \\
\hline Near large vessel & $28(40.2 \%)$ & $107(30.1 \%)$ & $=0.0787$ \\
\hline Brain invasion ** & $16(26.2 \%)$ & $63(21.1 \%)$ & $=0.3900$ \\
\hline WHO grade I vs. II/III & $35(51.5 \%) / 33(48.5 \%)$ & $227(63.9 \%) / 128(36.4 \%)$ & $=0.0615$ \\
\hline Simpson grade $<$ III $/ \geq$ III ** & $18(58 \%) / 13(41.9 \%)$ & $81(73.6 \%) / 29(26.4 \%)$ & $=0.1013$ \\
\hline Ki67 (\%) * & $3(3-5)$ & $3(3-5)$ & $=0.3223$ \\
\hline Mitosis & & & \\
\hline $\begin{array}{c}<4 / 10 \mathrm{HPF} / 4-20 / 10 \mathrm{HPF} / \\
>20 / 10 \mathrm{HPF} * *\end{array}$ & $39(69.6 \%) / 24(42.9 \%) / 3(5.4 \%)$ & $268(78.4 \%) / 70(20.5 \%) / 4(1.2 \%)$ & $=0.0040$ \\
\hline $\begin{array}{l}\text { Preoperative edema } \\
\text { Non/ } \leq \text { tumor volume/ } \\
\text { >tumor volume }\end{array}$ & $\begin{array}{c}14(21.5 \%) / 29(44.6 \%) / 22 \\
(33.8 \%)\end{array}$ & $\begin{array}{c}136(41.3 \%) / 107(32.5 \%) / 86 \\
(26.1 \%)\end{array}$ & $=0.0079$ \\
\hline Preoperative KPS $\leq 60 \%$ & $10(14.7 \%)$ & $10(2.8 \%)$ & $=0.0003$ \\
\hline Surgical Management & & & \\
\hline Embolization & $1(1.5 \%)$ & $0(0 \%)$ & $=0.0555$ \\
\hline Surgical time $(\min ) *$ & $320(259.2-377)$ & $217(169-290)$ & $<0.0001$ \\
\hline Intraoperative blood loss $(\mathrm{mL})$ * & $1125(525-1675)$ & $450(300-1100)$ & $<0.0001$ \\
\hline \multicolumn{4}{|l|}{ Postoperative Complications } \\
\hline Acute renal failure & $2(2.9 \%)$ & $0(0 \%)$ & $=0.0067$ \\
\hline Pneumonia & $13(19.1 \%)$ & $5(1.4 \%)$ & $<0.0001$ \\
\hline Sepsis & $2(2.9 \%)$ & $0(0 \%)$ & $=0.0067$ \\
\hline Pulmonary embolism & $10(14.7 \%)$ & $16(4.5 \%)$ & $=0.0043$ \\
\hline Seizure ${ }^{* *}$ & $21(36.8 \%)$ & $50(15.2 \%)$ & $=0.0003$ \\
\hline Re-craniotomy ** & $22(41.5 \%)$ & $36(11.4 \%)$ & $<0.0001$ \\
\hline Hospital LOS (days) * & $15.5(10.3-23)$ & $8(7-11)$ & $<0.0001$ \\
\hline ICU LOS (days) * & $6(2-15)$ & $1(1-1)$ & $<0.0001$ \\
\hline \multicolumn{4}{|l|}{$\mathrm{Hb}$ values and Transfusion rates } \\
\hline $\mathrm{Hb}$ value (admission) $(\mathrm{g} / \mathrm{dL}) *$ & $13.8(12.8-14.7)$ & $14.1(13.3-14.8)$ & $=0.1072$ \\
\hline Anaemia rate at admission & $12(17.7 \%)$ & $22(6.2 \%)$ & $=0.0015$ \\
\hline $\mathrm{Hb}$ value (discharge) $(\mathrm{g} / \mathrm{dL})$ * & $9.8(8.7-10.5)$ & $11(10-12)$ & $<0.0001$ \\
\hline Anaemia rate at discharge & $66(97.0 \%)$ & $290(81.6 \%)$ & $=0.0002$ \\
\hline Platelet transfusion rate & $7(10.3 \%)$ & $2(0.6 \%)$ & $<0.0001$ \\
\hline FFP transfusion rate & $10(14.7 \%)$ & $1(0.3 \%)$ & $<0.0001$ \\
\hline Fibrinogen transfusion rate & $19(27.9 \%)$ & $5(1.4 \%)$ & $<0.0001$ \\
\hline PCC transfusion rate & $10(14.7 \%)$ & $9(2.5 \%)$ & $=0.0002$ \\
\hline
\end{tabular}

* Results are expressed as median (IQR). BMI, Body Mass Index; ASA, American Society of Anaesthesiologists; WHO, World Health Organization; KPS, Karnofsky performance scale; HPF, High power fields; Hb, Haemoglobin; RBC, Red blood cell; FFP, Fresh frozen plasma; ICU, Intensive care unit; LOS, Length of stay; PCC, Prothrombin complex concentrate. Note: Bold $p$-value = statistically significant. ** Data not from all patients available. 
Intraoperatively, surgical time was significantly longer in patients with RBC transfusion (320 (259.2-377) min) compared to patients without RBC transfusion (217 (169-290) min; $p<0.0001)$. In addition, the amount of blood loss also differed significantly between both groups (1125 (525-1675) ml vs. 450 (300-1100) ml; $p<0.0001)$.

Regarding the transfusion rate of other blood products, transfusion rate of platelets (10.3\% vs. $0.6 \% ; p<0.0001)$, FFP $(14.7 \%$ vs. $0.3 \% ; p<0.0001)$, fibrinogen $(27.9 \%$ vs. $1.4 \% ; p<0.0001)$ and PCC $(14.7 \%$ vs. $2.5 \% ; p=0.0002)$ differed significantly between the RBC-transfusion and non-RBC transfusion group, respectively.

Hospital LOS was significantly longer in transfused patients (15.5 (10.3-23) days) compared to non-transfused patients (8 (7-11) days; $p<0.0001)$. In addition, postoperative complication rate was significantly higher in patients with RBC transfusion regarding acute renal failure $(p=0.0067)$, pneumonia $(p<0.0001)$, sepsis $(p=0.0067)$, pulmonary embolism $(p=0.0043)$, seizures $(p=0.0003)$ and re-craniotomy due to bleeding or swelling $(p<0.0001)$ compared to patients without RBC transfusion (Table 1).

\subsection{Risk Factors for RBC Transfusions}

For transfusion of RBC units in all patients $(n=423)$, the analyzed risk factors are summarized in Table 2. Of all analyzed factors, anaemia at hospital admission $(p=0.0015)$, age at surgery $(p=0.0153)$, elderly patients $(\geq 75$ years $)(p=0.0068)$, ASA score $(p<0.0001)$, cardiovascular disease $(p=0.0107)$, diabetes $(p=0.0210), \operatorname{KPS} \leq 60 \%(p=0.0003)$, preoperative edema $(p=0.0079)$, tumor size $(p<0.0001)$, mitosis rate $(p=0.0040)$, surgical time $(p<0.0001)$ and intraoperative blood loss $(p<0.0001)$ were significantly associated with the risk of RBC transfusion. Multivariate analyses of all factors that showed significant influence in univariate analyses $(p<0.05)$ were performed, respectively. After logistic regression, ASA score $(p=0.0247)$, tumor size $(p=0.0006)$, surgical time $(p=0.0018)$ and intraoperative blood loss $(p<0.0001)$ remained as independent risk factors for perioperative RBC transfusion (Table 2).

Table 2. Risk factors for RBC transfusion.

\begin{tabular}{|c|c|c|c|c|c|}
\hline Risk Factor & Univariate Analysis & Multivariate Analysis & & & \\
\hline & $p$-Value & $p$-Value & OR & $\mathbf{R R}$ & $95 \% \mathrm{CI}$ \\
\hline Anaemia at admission & $=0.0015$ & $=0.0900$ & 1.02 & 2.77 & $-0.12-1.46$ \\
\hline Age & $=0.0153$ & $=0.5567$ & 0.36 & 0.67 & $-0.07-0.03$ \\
\hline Elderly ( $\geq 75$ years) & $=0.0068$ & $=0.0905$ & 0.46 & 0.90 & $-0.47-1.31$ \\
\hline ASA score & $<0.0001$ & $=0.0247$ & 1.48 & 8.74 & \\
\hline ASA score 2-1 & & & & & $-4.84-0.62$ \\
\hline ASA score 3-2 & & & & & $-2.02-0.08$ \\
\hline Cardiovascular disease & $=0.0107$ & $=0.0700$ & 1.21 & 3.47 & $-0.03-1.07$ \\
\hline Diabetes & $=0.0210$ & $=0.4369$ & 0.47 & 0.92 & $-1.01-0.31$ \\
\hline Preoperative KPS $\leq 60 \%$ & $=0.0003$ & $=0.2309$ & 0.52 & 1.08 & $-0.39-1.24$ \\
\hline Preoperative edema & $=0.0079$ & $=0.7438$ & 0.16 & 0.76 & \\
\hline$\leq$ tumor volume-Non & & & & & $-1.41-1.02$ \\
\hline >tumor volume & & & & & $-0.66-1.78$ \\
\hline$\leq$ tumor volume & & & & & $-0.66-1.78$ \\
\hline Tumor size & $<0.001$ & $=0.0006$ & 3.03 & 10.10 & $-0,04-0,01$ \\
\hline Mitosis & $=0.0040$ & $=0.3686$ & 0.24 & 1.10 & $-0.04-0.01$ \\
\hline$>4-20 / 10 \mathrm{HPF}$ & & & & & $-1.56-0.73$ \\
\hline$<4 / 10 \mathrm{HPF}$ & & & & & $-1.00-0.10$ \\
\hline$>20 / 10 \mathrm{HPF}$ & & & & & $-3.64-2.67$ \\
\hline $4-20 / 10 \mathrm{HPF}$ & & & & & $-3.04-2.07$ \\
\hline Surgical time & $<0.0001$ & $=0.0018$ & 2.11 & 7.10 & $-0.01-0.00$ \\
\hline Intraoperative blood loss & $<0.0001$ & $<0.0001$ & 4.38 & 16.80 & $-0.01-0.00$ \\
\hline
\end{tabular}

Note: $p$-value = statistically significant in univariate analysis, underlined bold $p$-value $=$ statistically significant in multivariate analysis; ASA, American Society of Anaesthesiologists; KPS, Karnofsky performance scale; HPF, High power fields; OR, Odds Ratio; RR, Risk Ratio; CI, Confidence interval. 
Furthermore, univariate linear regression analysis revealed a significant correlation between tumor size and number of transfused RBC units $\left(R^{2}=0.0183 ; p<0.0001\right)$ (Figure 2).

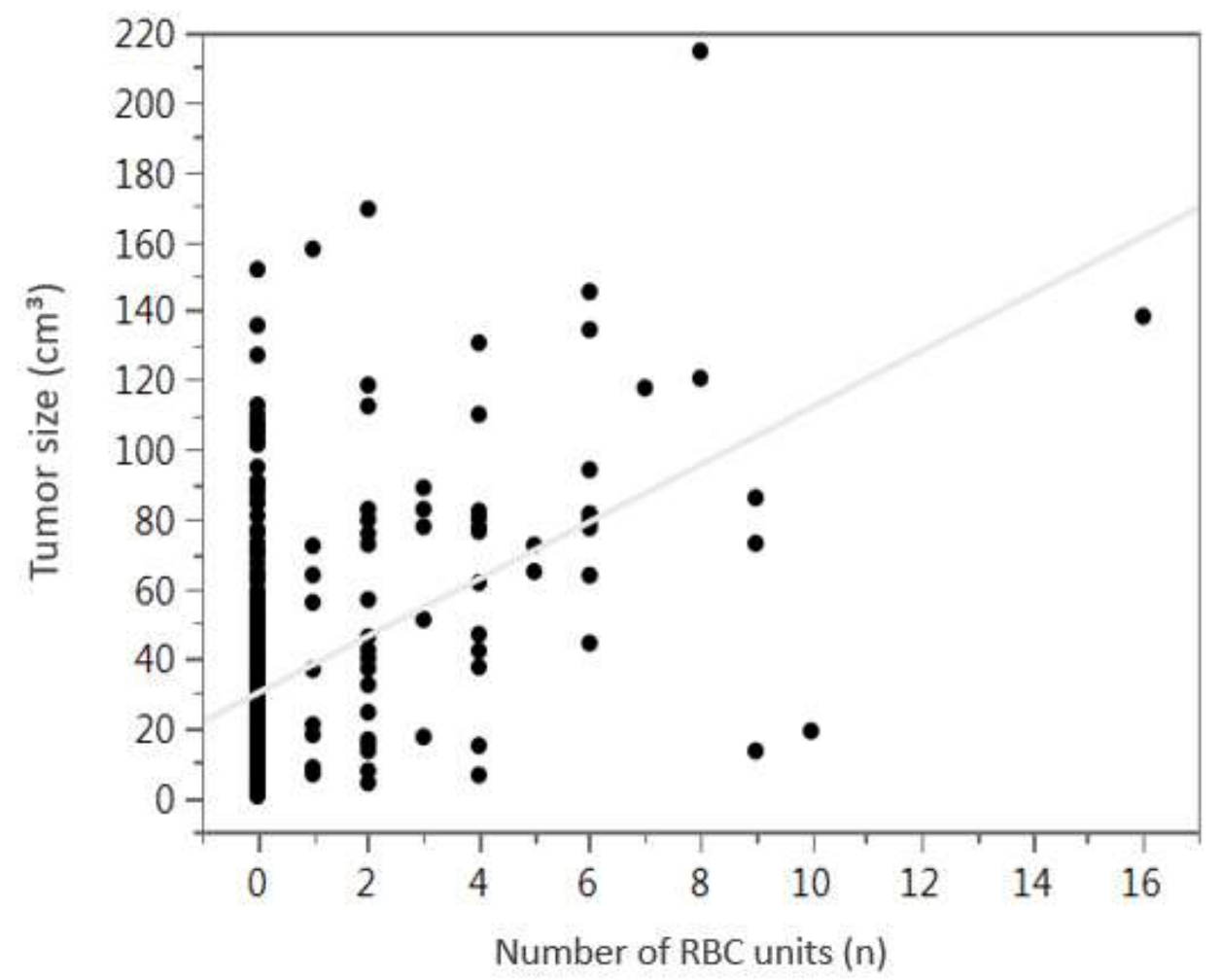

Figure 2. Simple linear regression illustrates the significant correlation of tumor size and number of transfused RBC units $\left(\mathrm{R}^{2}=0.0183 ; p<0.0001\right)$; RBC, red blood cell.

\subsection{Survival}

Kaplan-Meier curves revealed significant influence on overall survival by RBC transfusion, preoperative anaemia, smoking, cardiovascular disease, preoperative KPS $\leq 60 \%$ and age (elderly patients $\geq 75$ years). No influence was observed for diabetes and WHO grade (Figure 3). 
A

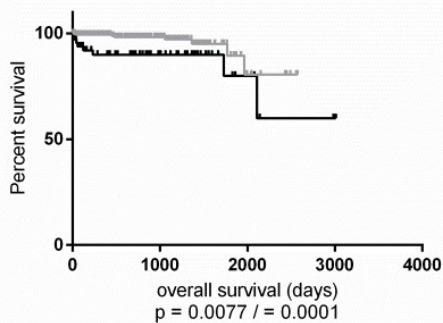

C

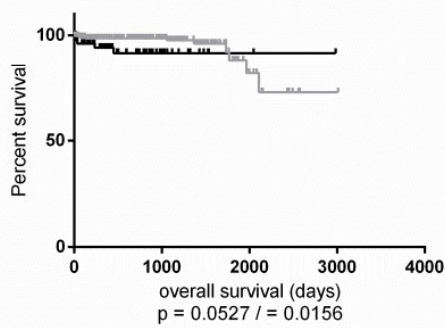

E

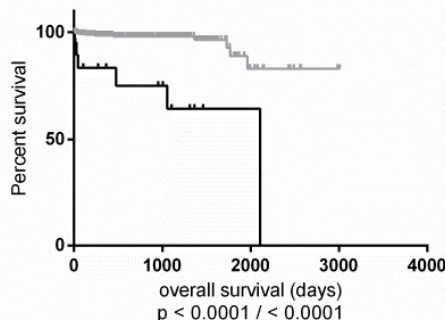

G

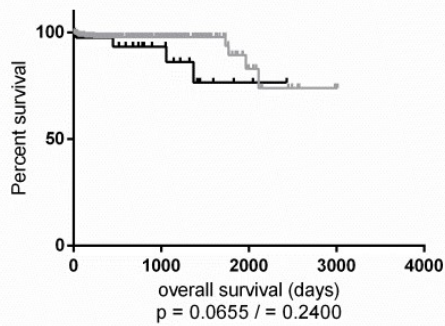

B

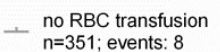
$\mathrm{n}=351$; events: 8

- $\begin{aligned} & \mathrm{RBC} \text { transfusion } \\ & \mathrm{n}=68 \text {; events: } 8\end{aligned}$

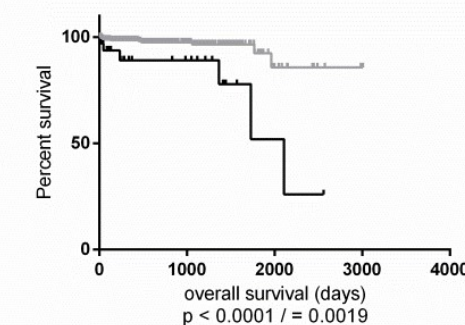

_ no preoperative anemia

$n=385$; events: 10

_. preoperative anemia

D

$-\stackrel{n=3 m o k i n g}{n=332 ; \text { events: } 10}$

_. smoking

$\mathrm{n}=82$; events: 5

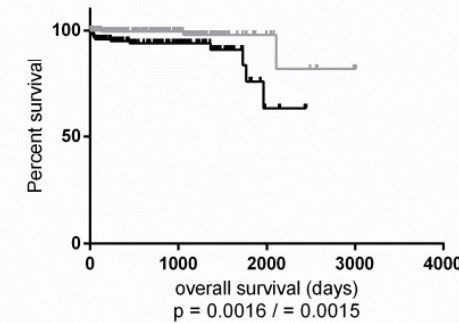

no cardiovascular disease

$\mathrm{n}=258$; events: 3

- cardiovascular disease

$n=156$; events: 12

F

$\mathrm{KPS}>60 \%$
$\mathrm{n}=396$; events: 10

- KPS $\leq 60 \%$

$\mathrm{n}=21$; events: 6

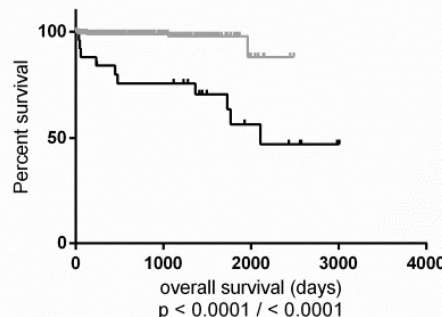

non elderly

$\mathrm{n}=394$; events: 6

_ elderly

$n=25$; events: 10

H

no diabetes

$\mathrm{n}=379$; events: 11

_. diabetes

$n=44$; events: 4

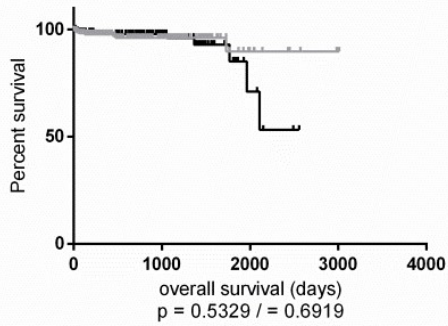

— WHO grade I

$\mathrm{n}=259$; events: 8

_ WHO grade II/ III

$n=158$; events: 8

Figure 3. (A) Kaplan-Meier curve illustrates the overall survival in the cohort between patients with RBC transfusion and without RBC transfusion (B) Overall survival by preoperative anaemia and no preoperative anaemia (C) Overall survival by smoking and no smoking (D) Overall survival by cardiovascular disease and no cardiovascular disease (E) Overall survival by KPS $>60 \%$ and KPS $\leq 60 \%$ (F) Overall survival by elderly patients ( $\geq 75$ years) and non-elderly patients ( $<75$ years) (G) Overall survival by diabetes and no diabetes $(\mathbf{H})$ Overall survival by WHO grade I and WHO grade II/III. $p$-values are obtained from Log-rank test/Wilcoxon Test.

\section{Discussion}

The present study examined the clinical outcome and risk factors of perioperative $\mathrm{RBC}$ transfusion in patients undergoing primary resection of skull base and non-skull base meningioma. Of all patients, 34 out of 423 (8\%) were anaemic and 389 out of $423(92.0 \%)$ did not suffer from preoperative anaemia. Overall, 68 out of $423(16.1 \%)$ patients received 
RBC transfusion and 355 out of 423 (83.9\%) patients did not receive RBC transfusion. Preoperative anaemia rate was significantly higher in the RBC transfusion group compared to the non-RBC transfusion group. Patients with RBC transfusion had increased postoperative complication rate and prolonged hospital LOS. Multivariate analyses revealed that ASA score, tumor size, surgical time and intraoperative blood loss are independent risk factors for RBC transfusion. In addition, Kaplan-Meier curves revealed significant influence on overall survival by preoperative anaemia, RBC transfusion, smoking, cardiovascular disease, preoperative KPS $\leq 60 \%$ and age (elderly $\geq 75$ years).

\subsection{Preoperative Anaemia and Clinical Outcome of RBC Transfusion}

Recent findings in elective cranial neurosurgical patients have demonstrated, that preoperative anaemia is independently associated with an increased risk of 30-day postoperative mortality and morbidity compared to non-anaemic patients [6]. Furthermore, anaemia represents a major cause for RBC transfusion [19]. In our study, preoperative anaemia rate was low $(8 \%)$ in patients undergoing primary craniotomy for meningioma disease. In comparison, anaemia rate in a study by Bydon et al. was higher with $21.4 \%$. In this study, patients undergoing elective cranial neurosurgeries due to a variety of tumors were included [6]. The presented low preoperative anaemia rate in our study may also be explained by a potential preselection in neurosurgical patients since the natural course of meningioma disease allows elective planning of the operation. Patients with comorbidities associated with anaemia are often not suitable for cranial surgery and thus are put on a watch and wait strategy in a single case decision. It is noteworthy, that there are studies using different definitions of anaemia (e.g., by haematocrit) [20]. Our study defined anaemia according to the $\mathrm{WHO}$ definition by $\mathrm{Hb}$ value, therefore in these cases, any comparison has to be done carefully.

Overall, preoperative anaemia rate was significantly higher in the RBC transfusion group $(17.7 \%)$ compared to the non-RBC transfusion group $(6.2 \% ; p=0.0015)$. Similar results of anaemic patients being at greater risk for $\mathrm{RBC}$ transfusion were obtained in another study of patients undergoing elective cranial surgery. Here, RBC transfusion rates in severe-moderate and mild anaemia were significantly higher compared to non-anaemic patients, respectively ( $33.7 \%$ vs. $9.9 \%$ vs. $3.6 \%$; $p<0.0001$ ) [20]. In total, transfusion rate of all patients in our study was $16.1 \%$ (68 out of 423 ). These results are in accordance with a study by Langman et al., who evaluated 37 neurosurgical patients with skull base meningioma, whereas 7 out of 37 (18.9\%) patients received RBC transfusion [10].

Our results also revealed that preoperative KPS $\leq 60$ was more frequent in transfused patients $(14.7 \%)$ compared to non-transfused patients $(2.8 \% ; p=0.0003)$. Considering the fact that anaemia rate was higher in transfused patients, these results demonstrate that anaemia is accompanied with comorbidities and decreases the risk of functional decline in older adults. It is reported in literature that anaemia is associated with weakened muscle strength, mobility limitations and the ability to keep balance [21].

In our study patients with RBC transfusion had an increased risk of postoperative complications as well as prolonged hospital LOS. Similarly, Cohen et al. assessed the impact of RBC transfusion in cranial surgery through the National Surgical Quality Improvement Program database and demonstrated that patients who received RBC transfusion had an increased risk of postoperative complications, return to the operating room, prolonged hospital LOS, and higher mortality rates compared to non-transfused patients [8]. In general, patients who receive RBC transfusion are typically in a graver medical condition than those who do not [22].

Regarding overall survival, Kaplan-Meier curves revealed that preoperative anaemia and RBC transfusion had a significant influence on overall survival in meningioma patients. Since this is the first time investigating a large cohort of meningioma patients so far, comparison with other studies is not feasible. 


\subsection{Risk Factors of RBC Transfusion}

In our study, univariate analyses revealed that preoperative anaemia, age (elderly $\geq 75$ years), comorbidities (cardiovascular disease and diabetes), ASA score, preoperative edema, mitosis, tumor size, surgical time and intraoperative blood loss were a risk factors for RBC transfusion in meningioma patients. Multivariate analyses showed that ASA score, tumor size, surgical time and intraoperative blood loss remained as independent risk factors for $\mathrm{RBC}$ transfusion.

So far, there are only a few clinical studies investigating RBC transfusion in brain tumor surgery $[10,23,24]$. With a focus on independent risk factors for RBC transfusion in skull base meningiomas a study by Lagman et al [10]. showed that the skull base was an independent risk factor for RBC transfusion. In addition, a meningioma size greater than $5 \mathrm{~cm}$ was also a risk factor for transfusion. However, the authors state, that they were unable to determine whether tumor size was an independent risk factor, as sample size precluded multivariate analyses [10]. Our study includes 423 meningioma patients with skull base and non-skull base tumors and revealed tumor size as an independent risk factor for RBC transfusion. Especially large skull base meningiomas are often high vascularized and can enhance large vessels. Considering this fact, the intraoperative blood loss could be high since the vascular supply might be located within the tumor.

Our results demonstrate that there was a positive correlation between existing cardiovascular disease and the transfusion of RBC units. Especially in patients with underlying chronic cardiac condition, anaemia represents a risk factor for adverse cardiovascular events. Therefore, according to the German transfusion guidelines, RBC transfusion is recommended in patients with cardiovascular risk factors and limited compensatory capacity or in patients with clinical symptoms of anaemic hypoxia at $\mathrm{Hb} \leq 8 \mathrm{~g} / \mathrm{dL}$. In patients without underlying cardiovascular disease or symptoms of impaired compensatory capacity, $\mathrm{RBC}$ transfusion is not recommended at $\mathrm{Hb} \leq 8 \mathrm{~g} / \mathrm{dL}$ [25]. This transfusion strategy in these patients may lead to higher RBC transfusion rates in patients with underlying cardiovascular disease in this study.

Simple linear regression also revealed a significant correlation of tumor volume and number of RBC units transfused which to our mind is comprehensible and highlights the reliability of our data.

In multivariate analyses preoperative anaemia did not remain an independent risk factor for RBC transfusion. In our study only 34 out of $423(8 \%)$ patients were anaemic. Sample size did not preclude multivariate analyses. Here, blood loss due to large tumors or localization near large vessels is likely the main trigger for RBC transfusion in meningioma patients paired with a potential preselection that may mask the effect of preoperative anaemia in multivariate analysis.

Our data suggests that more patients were embolized in the transfusion group, however this did not reach statistical significance due to limited sample size of embolized patients. A study by Manaka et al. analyzed 69 patients with preoperative embolization for intracranial meningioma resection and revealed that preoperative embolization reduces intraoperative blood loss and surgical time by softening tumor consistency [26]. Considering our results of higher RBC transfusions in patients with larger tumors, greater amounts of intraoperative blood loss and longer surgical times, preoperative embolization of meningiomas may be helpful to reduce the need for allogeneic RBC units.

\subsection{Strategies and Alternatives to RBC Transfusion}

Our study revealed that $R B C$ transfusion in meningioma patients is associated with an increased risk for postoperative complications and prolonged hospital LOS. In addition, RBC transfusion had significant influence on overall survival.

In order to minimize the risks associated with perioperative RBC transfusion, Patient Blood Management (PBM) has evolved within the last decade. PBM is an evidence-based, patient-centered and multidisciplinary approach in order to minimize the risks associated with anaemia in surgical patients [27]. The concept of PBM aims to reduce preoperative 
anaemia (pillar 1), minimize iatrogenic blood loss (pillar 2) and optimize patient specific tolerance of anaemia (pillar 3) in order to maintain the patient's own blood volume and reduce allogeneic RBC transfusions [28].

As shown above, intraoperative blood loss represents an independent risk factor for perioperative RBC transfusion in multivariate analysis $(p<0.0001)$. Therefore, efforts should focus on reducing intraoperative iatrogenic blood loss and optimizing coagulopathy. Adequate surgical haemostasis, blood conservation techniques and coagulation management are seen as a precondition before RBC transfusion is considered. To optimize coagulopathy Meybohm et al. recommended the use of a coagulation algorithm, maintenance of basic conditions for haemostasis (body temperature $>36^{\circ} \mathrm{C}$, ionized calcium $>1.1 \mathrm{mmol} / \mathrm{L}$, $\mathrm{pH}>7.2$ ) or point-of-care diagnostics.

Moreover, preoperative anaemia was associated with an increased number of RBC transfusions in univariate analysis $(p=0.0015)$. Consequently, preoperative anaemia management should be considered in meningioma patients and the cause of anaemia should be addressed accordingly. Depending on the cause of preoperative anaemia, the most common ways to treat preoperative anaemia are the use of iron supplementation and erythropoiesis stimulating agents [29]. In case of preoperative iron deficiency anaemia (IDA), recent studies proved that the administration of intravenous iron reduces the need for RBC transfusion and is associated with a shorter hospital LOS [30,31]. Triphaus et al. evaluated the effect of iron supplementation in patients with IDA undergoing major elective surgery. All iron-supplemented IDA patients required less RBC units during the postoperative period (31.5\%) compared to anaemic patients without iron treatment $(42.5 \%)$. In addition, hospital LOS was significantly reduced by 2.8 days in iron-supplemented IDA patients $(13.9( \pm 0.8)$ days $)$ compared to anaemic patients without iron treatment (16.7 ( \pm 0.7$) ; p<0.01)$ [19].

Especially in neurosurgical patients, preoperative strategies for identification and treatment of preoperative anaemia as well as intraoperative strategies like correction of coagulopathy or use of anti-fibrinolytic drugs are highly important [32]. Studies revealed that anaemia contributes to reduced cerebral oxygen delivery with secondary hypoxic insult to the injured brain. In healthy volunteers, anaemia-induced cognitive dysfunction is evident at $\mathrm{Hb}$ value between 5.0 and $6.0 \mathrm{~g} / \mathrm{dl}$ [33].

Finally, RBC transfusions have shown to significantly increase postoperative morbidity and mortality, therefore putting an enormous pressure on health care facilities [34]. With focus on preoperative anaemia correction, an assessment of cost benefits by intravenous iron supplementation prior to elective abdominal surgery has demonstrated hospital cost savings of $€ 786$ per case based on the reduced number of transfused RBC units and shorter hospital LOS [35].

\subsection{Limitations}

Our study is limited by the retrospective, single center design. In addition, the cause of preoperative anaemia cannot be discerned with the database, however ID may be a potential and common cause of anaemia. Furthermore, the anaemia-rate is quite low and introduces a selection bias compared to population-based studies. Furthermore, the effectiveness of presurgical embolization in reducing RBC transfusion requirements during elective meningioma resection should be evaluated in future studies.

\section{Conclusions}

In conclusion, the number of anaemic patients was significantly higher in the transfused patient group. We identified several risk factors for RBC transfusion, which include ASA score, tumor size, surgical time and intraoperative blood loss. Regarding clinical outcome, transfused patients had longer hospital LOS and higher postoperative complication rates. In the past, studies on patients undergoing major surgical procedures have demonstrated that anaemia and RBC transfusions are associated with increased postoperative complications, morbidity and mortality. Especially in a neurosurgical patient population, 
preoperative anaemia identification and treatment is crucial. Future prospective studies need to evaluate the potential clinical benefit of preoperative anaemia management as part of a holistic PBM program in meningioma patients if anaemia or large tumors are present. Preoperatively, consideration should be given to the correction of underlying coagulopathy and anaemia, by the use of iron replacement or erythropoietin. Intraoperatively, the use of anti-fibrinolytic drugs or continuous $\mathrm{Hb}$ monitoring should also be considered in future trials. Last, the association of different anaemia grades on clinical outcome and transfusion requirements should be considered in future analyses.

Author Contributions: Conceptualization, P.B., V.N. and V.S.; Data curation, P.B., V.N. and S.K.; Formal analysis, P.B., V.N., F.J.R., D.D. and C.S.; Investigation, P.B., V.N., D.M., P.M. and P.N.H.; Methodology, P.B. and D.D.; Project administration, P.B. and C.S.; Supervision, P.B., F.J.R., P.N.H., V.S. and C.S.; Validation, E.H.; Writing-Original draft, V.N., D.M. and P.B.; Writing-Review and editing, P.B., V.N., D.M., S.K., A.B., F.J.R., F.P., D.D., M.W.R., C.S., E.H., K.Z., P.N.H., V.S. and P.M. All authors have read and agreed to the published version of the manuscript.

Funding: This research received no external funding.

Institutional Review Board Statement: The study was approved by the local ethics committee of the University Hospital of Frankfurt and the University Cancer Centre (UCT) Frankfurt/Main (EC number UCT-65-2020, date of acceptance 5 January 2021). Patients gave written consent to the use of blinded clinical data and the use of tissue specimens for scientific purpose at admission. We confirm that we have read the Journal's position on issues involved in ethical publication and affirm that this report is consistent with those guidelines.

Informed Consent Statement: Informed consent was obtained from all subjects involved in the study. Patients gave written consent to the use of blinded clinical data and the use of tissue specimens for scientific purpose at admission.

Data Availability Statement: The data presented in this study are available on request from the corresponding author. The data are not publicly available due to ethical restrictions.

Conflicts of Interest: The authors declare no conflict of interest.

\section{References}

1. Muñoz, M.; Gómez-Ramírez, S.; Campos, A.; Ruiz, J.; Liumbruno, G.M. Pre-operative anaemia: Prevalence, consequences and approaches to management. Blood Transfus. 2015, 13, 370-379.

2. Musallam, K.M.; Tamim, H.M.; Richards, T.; Spahn, D.R.; Rosendaal, F.R.; Habbal, A.; Khreiss, M.; Dahdaleh, F.S.; Khavandi, K.; Sfeir, P.M.; et al. Preoperative anaemia and postoperative outcomes in non-cardiac surgery: A retrospective cohort study. Lancet 2011, 378, 1396-1407. [CrossRef]

3. Hare, G.M.; Tsui, A.K.; McLaren, A.T.; Ragoonanan, T.E.; Yu, J.; Mazer, C.D. Anemia and cerebral outcomes: Many questions, fewer answers. Anesth. Analg. 2008, 107, 1356-1370. [CrossRef]

4. Utter, G.H.; Shahlaie, K.; Zwienenberg-Lee, M.; Muizelaar, J.P. Anemia in the setting of traumatic brain injury: The arguments for and against liberal transfusion. J. Neurotrauma 2011, 28, 155-165. [CrossRef]

5. Baron, D.M.; Hochrieser, H.; Posch, M.; Metnitz, B.; Rhodes, A.; Moreno, R.P.; Pearse, R.M.; Metnitz, P. Preoperative anaemia is associated with poor clinical outcome in non-cardiac surgery patients. Br. J. Anaesth 2014, 113, 416-423. [CrossRef] [PubMed]

6. Bydon, M.; Abt, N.B.; Macki, M.; Brem, H.; Huang, J.; Bydon, A.; Tamargo, R.J. Preoperative anemia increases postoperative morbidity in elective cranial neurosurgery. Surg. Neurol. Int. 2014, 5, 156. [PubMed]

7. Hendrickson, J.E.; Hillyer, C.D. Noninfectious serious hazards of transfusion. Anesth. Analg. 2009, 108, 759-769. [CrossRef]

8. Cohen, J.A.; Alan, N.; Seicean, A.; Weil, R.J. Risk associated with perioperative red blood cell transfusion in cranial surgery. Neurosurg. Rev. 2017, 40, 633-642. [CrossRef] [PubMed]

9. Louis, D.N.; Perry, A.; Reifenberger, G.; von Deimling, A.; Figarella-Branger, D.; Cavenee, W.K.; Ohgaki, H.; Wiestler, O.D.; Kleihues, P.; Ellison, D.W. The 2016 World Health Organization Classification of Tumors of the Central Nervous System: A summary. Acta Neuropathol. 2016, 131, 803-820. [CrossRef]

10. Lagman, C.; Sheppard, J.P.; Beckett, J.S.; Tucker, A.M.; Nagasawa, D.T.; Prashant, G.N.; Ziman, A.; Yang, I. Red Blood Cell Transfusions Following Resection of Skull Base Meningiomas: Risk Factors and Clinical Outcomes. J. Neurol. Surg. Part B Skull Base 2018, 79, 599-605. [CrossRef]

11. Naidech, A.; Jovanovic, B.; Wartenberg, K.; Parra, A.; Ostapkovich, N.; Connolly, E.; Mayer, S.A.; Commichau, C. Higher hemoglobin is associated with improved outcome after subarachnoid hemorrhage. Crit. Care Med. 2007, 35, 2383-2389. [CrossRef] [PubMed] 
12. Wartenberg, K.; Schmidt, J.M.; Claassen, J.; Temes, R.; Frontera, J.; Ostapkovich, N.; Parra, A.; Connolly, E.S.; Mayer, S.A. Impact of medical complications on outcome after subarachnoid hemorrhage. Crit. Care Med. 2006, 34, 617-623. [CrossRef] [PubMed]

13. Stein, M.; Brokmeier, L.; Herrmann, J.; Scharbrodt, W.; Schreiber, V.; Bender, M.; Oertel, M.F. Mean hemoglobin concentration after acute subarachnoid hemorrhage and the relation to outcome, mortality, vasospasm, and brain infarction. J. Clin. Neurosci. 2014, 22, 530-534. [CrossRef] [PubMed]

14. Epstein, D.S.; Mitra, B.; O’Reilly, G.; Rosenfeld, J.V.; Cameron, P.A. Acute traumatic coagulopathy in the setting of isolated traumatic brain injury: A systematic review and meta-analysis. Injury 2014, 45, 819-824. [CrossRef]

15. Wirsching, H.G.; Morel, C.; Gmür, C.; Neidert, M.C.; Baumann, C.R.; Valavanis, A.; Rushing, E.J.; Krayenbühl, N.; Weller, M. Predicting outcome of epilepsy after meningioma resection. Neuro Oncol. 2016, 18, 1002-1010. [CrossRef]

16. Baumgarten, P.; Gessler, F.; Schittenhelm, J.; Skardelly, M.; Tews, D.S.; Senft, C.; Dunst, M.; Imoehl, L.; Plate, K.H.; Wagner, M.; et al. Brain invasion in otherwise benign meningiomas does not predict tumor recurrence. Acta Neuropathol. 2016, 132, 479-481. [CrossRef] [PubMed]

17. Simpson, D. The Recurrence of intracranial meningiomas after surgical treatment. J. Neurol. Neurosurg. Psychiatry 1957, 20, 22. [CrossRef] [PubMed]

18. World Health Organization. Haemoglobin Concentrations for the Diagnosis of Anaemia and Assessment of Severity. Available online: https:/ / www.who.int/vmnis/indicators/haemoglobin/en/ (accessed on 21 June 2021).

19. Triphaus, C.; Judd, L.; Glaser, P.; Goehring, M.H.; Schmitt, E.; Westphal, S.; Füllenbach, C.; Lindau, S.; Zacharowski, K.; Meybohm, P.; et al. Effectiveness of preoperative iron supplementation in major surgical patients with iron deficiency: A prospective observational study. Ann. Surg. 2019. [CrossRef]

20. Alan, N.; Seicean, A.; Seicean, S.; Neuhauser, D.; Weil, R.J. Impact of preoperative anemia on outcomes in patients undergoing elective cranial surgery. J. Neurosurg. 2014, 120, 764-772. [CrossRef]

21. Kushang, V.P.; Jack, M.G. Prognostic implications of anemia in older adults. Haematologica 2009, 94, 1-2.

22. Glance, L.G.; Dick, A.W.; Mukamel, D.B.; Fleming, F.J.; Zollo, R.A.; Wissler, R.; Salloum, R.; Meredith, U.W.; Osler, T.M. Association between intraoperative blood transfusion and mortality and morbidity in patients undergoing noncardiac surgery. Anesthesiology 2011, 114, 283-292. [CrossRef] [PubMed]

23. Mebel, D.; Akagami, R.; Flexman, A.M. Use of tranexamic acid is associated with reduced blood product transfusion in complex skull base neurosurgical procedures: A retrospective cohort study. Anesth. Analg. 2016, 122, 503-508. [CrossRef]

24. Awada, W.N.; Mohmoued, M.F.; Radwan, T.M.; Hussien, G.Z.; Elkady, H.W. Continuous and noninvasive hemoglobin monitoring reduces red blood cell transfusion during neurosurgery: A prospective cohort study. J. Clin. Monit. Comput. 2015, 29, 733-740. [CrossRef]

25. Bundesärztekammer (BÄK). Guidelines for Therapy with Blood Components and Plasma Derivatives in Germany 2014. Available online: https:/ / www.bundesaerztekammer.de/fileadmin/user_upload/downloads/QLL_Haemotherapie_2014.pdf (accessed on 21 June 2021).

26. Manaka, H.; Sakata, K.; Tatezuki, J.; Shinohara, T.; Shimohigoshi, W.; Yamamoto, T. Safety and efficacy of preoperative embolization in patients with meningioma. J. Neurol. Surg. Part B Skull Base 2018, 79, S328-S333. [CrossRef]

27. Althoff, F.C.; Neb, H.; Herrmann, E.; Trentino, K.M.; Vernich, L.; Füllenbach, C.; Freedman, J.; Waters, J.H.; Farmer, S.; Leahy, M.F.; et al. Multimodal patient blood management program based on a three-pillar strategy: A systematic review and metaanalysis. Ann. Surg. 2019, 269, 794-804. [CrossRef]

28. Goodnough, L.T.; Shander, A. Patient blood management. Anesthesiology 2012, 116, 1367-1376. [CrossRef]

29. Meybohm, P.; Richards, T.; Isbister, J.; Hofmann, A.; Shander, A.; Goodnough, L.T.; Muñoz, M.; Gombotz, H.; Weber, C.F.; Choorapoikayil, S.; et al. Patient blood management bundles to facilitate implementation. Transfus. Med. Rev. 2017, 31, 62-71. [CrossRef]

30. Spahn, D.; Schoenrath, F.; Spahn, G.; Seifert, B.; Stein, P.; Theusinger, O.; Kaserer, A.; Hegemann, I.; Hofmann, A.; Maisano, F.; et al. Effect of ultra-short-term treatment of patients with iron deficiency or anaemia undergoing cardiac surgery: A prospective randomised trial. Lancet 2019, 393, 2201-2212. [CrossRef]

31. Froessler, B.; Palm, P.; Weber, I.; Hodyl, N.A.; Singh, R.; Murphy, E.M. The important role for intravenous iron in perioperative patient blood management in major abdominal surgery: A randomized controlled trial. Ann. Surg. 2016, 264, 41-46. [CrossRef] [PubMed]

32. Kisilevsky, A.; Gelb, A.W.; Bustillo, M.; Flexman, A.M. Anaemia and red blood cell transfusion in intracranial neurosurgery: A comprehensive review. Br. J. Anaesth. 2018, 120, 988-998. [CrossRef] [PubMed]

33. Weiskopf, R.B.; Kramer, J.H.; Viele, M.; Neumann, M.; Feiner, J.R.; Watson, J.J.; Hopf, H.W.; Toy, P. oxygen reverses deficits of cognitive function and memory and increased heart rate induced by acute severe isovolemic anemia. Anesthesiology 2002, 96, 871-877. [CrossRef] [PubMed]

34. Lefebvre, P.; Duh, M.S.; Buteau, S.; Bookhart, B.; Mody, S.H. Medical costs of untreated anemia in elderly patients with predialysis chronic kidney disease. J. Am. Soc. Nephrol. 2006, 17, 3497-3502. [CrossRef] [PubMed]

35. Froessler, B.; Rueger, A.M.; Connolly, M.P. Assessing the costs and benefits of perioperative iron deficiency anemia management with ferric carboxymaltose in Germany. Risk Manag. Healthc. Policy 2018, 11, 77-82. [CrossRef] [PubMed] 